the soybean and from the Tientsin bean, but neither weevil-infected beans nor dead beans sprout.

Another pool took care of oil supplies, principally peanut oil, but coco-nut and small amounts of other vegetable oils passed through the pool. Care was taken to see that reserves of salt were adequate.

A siege ration based on rice, beans, oil and salt is a definite improvement on one of rice alone; but it was not considered sufficient. To meet vitamin requirements large amounts of thiamin chloride were purchased in the United States and sent to Hong Kong by air, nicotinic acid was ordered in England but did not arrive prior to hostilities and three hundred tons of red palm oil were imported from Malaya. Arrangements were made with the fishing fleets to bring in the livers of all the large sharks caught, and shark liver oil, rich in vitamins $\mathbf{A}$ and $\mathbf{D}$, was extracted and stored in sealed tins. A simple technique was adopted for the extraction of a solution of vitamin $\mathrm{C}$ from pine needles-P. Massoniana is abundant on the island. Consideration was also given to the possibilities of creating reserves of soy sauce, salted and dried vegetables, dried seaweed and even dried grass, but they were turned down as either of little food value or impracticable. Inquiries were made in London regarding the possibility of starting a food yeast factory, and others in Honolulu regarding the possibility of growing brewer's yeast, for there were ample reserves of molasses and supplies of ammonia and superphosphate, but the War came before any large scheme could be put into operation, though trials were commenced.

Peanut meal, after the oil has been expressed, is pressed into cakes and sold almost exclusively in Hong Kong as fertilizer. This cake is unpalatable as human food, largely because the oils it contains rapidly go rancid, but the fresh meal, straight from the press, has not this objection. With the enthusiastic co-operation of a master baker and after about thirty trials, it was found possible to make a hard siegeration biscuit from this meal and whole wheat flour. Each biscuit, which weighed half an ounce and cost half a cent, contained more than a man's daily requirements of available iron, two biscuits enough nicotinic acid to prevent pellagra and four onough thiamin chloride to prevent beriberi on a polished rice diet. Government approved of the biscuit, and a start was made in producing them at the rate of two tons a day; a larger scheme for making eight tons daily was not implemented due to hostilities. The biscuits contained only 2 per cent water, and they were packed in petrol tins which were then sealed. On the day before the Japanese attacked, a satisfactory biscuit was made which contained added calcium carbonate and shark liver oil. Everybody liked the biscuits-all nationalities and all ages from six months to over eighty years-for they were tested in three hospitals (including a maternity hospital) before the scheme was placed before the Defence Council.

Another project which was adopted was the creation of a salt fish reserve. Within a month of the idea being conceived the factory was in operation. The idea was to salt fish of selected kinds in enormous wooden tubs and to leave them, weighted with stones, submerged in the pickle that was formed. The tubs were mostly made on the site from teak, but some old ones of China fir were purchased, after the godowns had been built, and some were so large that the wall of a building had to be pulled down in order to allow the entry of the tubs. The objective was a thousand tons, and more than six hundred tons were safely stored away when the blitz commenced.

The Japanese attacked and in seventeen days the Colony was in their hands and with it a very tidy reserve of firewood, rice and other foodstuffs, not to speak of a great wealth of merchandise.

On January 21, 1942, the civilian internment camp at Stanley was opened and there new problems had to be faced and solved. Much of the siege reserve of thiamin chloride was smuggled into this camp (and into the military camps), more than two hundred tins of siege biscuits, some shark liver oil and a drum or two of red palm oil. A valiant Chinese prepared shark liver oil during the whole period of internment and sent it into the camps through the International Red Cross. Space does not permit a consideration of the food problems of the internment camp, which were as interesting as they were novel.

\section{SCIENCE AND EDUCATION}

$\mathrm{A}$ SUCCESSFUL second conference on "Science and Education" was held by the Leeds Branch of the Association of Scientific Workers on December 15 and was attended by more than eighty people, including delegates from twelve organisations. Prof. W. T. Astbury was in the chair.

Prof. J. D. Bernal, in opening the Conference, said that although the Government has appointed an influential sub-committee to investigate the training and use of scientific man-power on a national level, local meetings can nevertheless do valuable work by maintaining intelligent pressure on those responsible for seeing that the necessary steps are in fact taken. While he agrees with the policy which has previously been put forward by the Association of Scientific Workers, in his view, recent events now make a big increase both in the scale and the speed of attainment of these objectives essential. Thus the application of atomic energy can lift the level of human existence on to an entirely new plane; but this will only be realized if accompanied by vast improvements in other technical and intellectual fields and, in con. sequence, education in science for every citizen has now become a necessity.

In working out the problems of the atomic bomb project, a new organisational technique of mass attack on a problem with full integration of scientific, technical and social aspects has been evolved. Such a technique will have to be adopted by Britain for other problems if she is to maintain her position relative to other nations. The ultimate social saving from research is usually out of all proportion to its cost, but, in addition, it is now widely recognized that the immediate saving may also be well worth while, as when the organisers of greyhound-racing propose to spend on investigating dog hysteria about half the total sum spent on our pre-war medical research.

The limit on our researches in the near future is not likely to be a financial one, but will be a result of the limited supply of trained scientific workers available. It is not that we lack resources of intelli. gence : about eight per cent of the population seemed to have I.Q.s of 130 or higher and could therefore benefit from a university course. To make use of this intelligence will represent an eightfold increase in the past university population. The difficulties in the way of such an expansion will have to be overcome by new lines of approach. The supply of 
teachers could be increased by drawing, perhaps part-time, on the fifty thousand industrial scientific workers not usually engaged in teaching. Senior students could also help with the more elementary teaching and perhaps provide a modified form of tutorial supervision.

The difficulties of space could also be overcome. Destroyed universities are being rebuilt all over Europe. In Riga, for example, students and staff are building their own university, and while this solution is scarcely necessary in Britain, unorthodox methods should not be excluded; thus, space in shadow factories and similar war buildings might be made available if it was pressed for hard enough. In Prof. Bernal's opinion, the universities should have no difficulty in getting the money necessary for their schemes provided the existing machinery for this purpose were used effectively. The University Grants Committee has assured universities that the Treasury would provide the funds if asked for them.

If this proposed expansion of the science faculties is thwarted by narrow-minded university authorities lest the balance of the universities be upset or their seclusion spoilt, then as once or twice before in our history, new universities will no doubt be founded elsewhere, and indeed in any event we must step up many of our technical colleges to the standard of the former Technische Hochschule in Germany.

In conclusion, Prof. Bernal said that the urgent need of Great Britain and the world for science is so great that it imposes on every man of science a definite duty to pass on his knowledge to others ; and effective channels must be provided through which this can be done.

In throwing open the subject for discussion, Prof. Astbury said that he has been somewhat depressed by his own experiences with science discussion groups for adults and he considers it essential to introduce the subject to the populace while they are still young. He does not share Prof. Bernal's view that extra money is available to the universities for the asking, since at Leeds they receive only $60-80$ per cent of their own estimated needs.

Mr. J. Maddison put in a plea for more importance to be attached to mechanical aids to teaching, including not only the film but also charts and improved text-books. He suggested the Association of Scientific Workers should press for the preparation of more and better teaching films. Mr. H. D. Dickinson stated that there is already a fringe of unsuitable students coming up with scholarships and he wonders whether the present methods do not sometimes select the most docile rather than the most able students; his experience with adult education has shown him that there is often a second flowering of intellectual ability later in life, and he suggested that any future system should include provision for such older students.

A number of speakers, including $\mathrm{Mr}$. P. G. 'Espinasse and Dr. Guter, stressed the amount of a teacher's time which is wasted on non-teaching duties because of the present absence of adequately trained laboratory assistance. Dr. Guter pointed out that on Teesideall the part-time degree teaching is done by those engaged in local industry, but this has resulted in excessive demands being made on the volunteers. $\mathrm{He}$ suggested that a system of time off from their regular daily work might be arranged for such teachers during the time of the present emergency.

Mr. M. Kline considers it is in the primary schools that most citizens must learn of science ; yet teaching conditions in them are unsatisfactory, so that science there has become an unreal thing of words and symbols, with blackboard work instead of experiments. Dr. A. J. P. Martin said it is depressing for men of science to encounter a complete lack of appreciation in many industrialists as to what science is all about, and it is to be hoped that a higher status for the sub. ject in both primary and secondary schools will help to spread a realization that there is more in scientific method than the simple details of the individual sciences.

Prof. Bernal, replying to the points made by these and other speakers, said he fully appreciated the importance of a really good primary education and, in view of the grievous shortage of scientific apparatus, it is shocking to hear of war stocks being destroyed; nevertheless, a good teacher can do a great deal in improvising experiments with everyday objects, and teachers' organisations should press for more research work into actual teaching methods to be carried out. The proportion of assistants available in university laboratories might be only one fiftieth of that in good industrial laboratories; university teachers are in part to blame for putting up with these conditions so long and so docilely. He was encouraged by what he heard of the possibility of increasing the supply of teachers with part-time workers. This scheme has the advantage of providing the teachers just where they are most needed ; but, clearly, a national scheme for part-time releases of government and industrial scientific workers for teaching is what is required. Warnings have been given that difficulty might be encountered in future in recruiting enough teachers of the required standard into the secondary schools, and Prof. Bernal regrets that the universities are stil. not to have the task of training all teachers. Finally, under the more positive policy towards industry which is being adopted by the present Government, there is a great need for every Government department to include a body of scientific workers engaged not only in technical but also in operational research, so that the methods of the Civil Service could be transformed into those appropriate for the new scientific age.

In concluding its business, the Conference, on the motion of Dr. A. H. Gordon, resolved to set up a small permanent committee representative of the organisations participating in the Conference to advise appropriate local bodies in Leeds on any aspect of local education and science.

E. G. Carter.

\section{DISEASE AND TROPICAL INDUSTRY}

$T$ HE report of the meeting of the Advisory Committee of the Ross Institute held in July last contains a valuable review by Dr. G. Macdonald of some of the diseases which interfere most severely with tropical industry. During the War, states Dr. Macdonald, the Army has learnt that, in the tropies, malaria is the most important cause both of incapacity and of the failure of whole projects. This is a lesson which tropical industry learnt years ago. Now methods of tackling malaria have, however, been developed. The two main developments originated in pre-war civilian practice. These are the eradication of anopheline vectors rather than the attack upon malaria itself; and the proof that the control of the adult mosquito is an economical as well as an effective method, which can be applied to rural communities at a cost which even the most primitive communities can bear. 